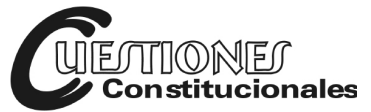

Revista Mexicana de Derecho Constitucional

Núm. 32, enero-junio 2015

\title{
¿DERECHOS HUMANOS O JURISPRUDENCIA INFALIBLE?
}

\author{
EITHER HUMAN RIGHTS OR INFALLIBLE PRECEDENTS?
}

\author{
José Ramón Cossío DÍAZ* \\ Roberto LARA CHAGOYÁN**
}

\begin{abstract}
RESUMEN: El nuevo modelo de control de la regularidad constitucional y el advenimiento del llamado "paradigma constitucionalista" demandan una buena cantidad de ajustes a nuestro sistema jurídico, tanto en el ámbito legislativo como en el jurisprudencial. Un mandato constitucional que condiciona estos cambios de manera preponderante es el principio pro persona. En este trabajo demostramos cómo la Suprema Corte de Justicia no ha sido precisamente consistente a la hora de conjugar este importante principio con los diferentes problemas que va resolviendo. A menos que pensemos que la jurisprudencia de la Corte es infalible, no encontramos ninguna razón que justifique su inaplicación a cargo de los jueces ordinarios mediante el control difuso. Tampoco podemos admitir que la Corte sea impermeable con relación al principio pro persona. En este trabajo, reflexionamos sobre estos problemas a propósito de un expediente de reciente resolución: la CT 299/2013.
\end{abstract}

Palabras clave: principio pro persona, control ex officio de la regularidad constitucional, jurisprudencia, norma jurídica, enunciado normativo (disposición), inaplicación, derechos humanos, paradigma constitucionalista, interpretación, analogía, infalibilidad.
ABSTRACT: The new model of constitutional adjudication and the advent of the so called "constitutionalist paradigm" demand quite a few adjustments in the Mexican legal system, both in the legislative field as in the judicial one. The "pro personae" principle must compel and inspire these changes. In this paper we will demonstrate how the Supreme Court of Justice has not been consistent at the time of expounding this important principle through judicial review. Unless we think that the Supreme Court is infallible, we do not find a reason that justifies this position. We cannot admit, either, that the Supreme Court is impermeable regarding the "pro personae" principle. In this paper, we reflect upon these issues by analyzing the recent decision in the C.T. 299/2013 (conflict in jurisdictional criteria).

Descriptors: "pro personae" principle, ex officio control, constitutional regularity, jurisprudence, juridical norm, legislative disposition, normative sentence, non-application, human rights, constitutional paradigm, interpretation, analogy, infallibility.

* Profesor de derecho en el ITAM y ministro de la Suprema Corte de Justicia de la Nación.

** Profesor en el posgrado de la Universidad de Guanajuato y secretario de estudio y cuenta en la Suprema Corte de Justicia de la Nación. 


\section{INTRODUCCIÓN}

Los días 13 y 14 de octubre de 2014, el tribunal pleno de la Suprema Corte de Justicia de la Nación resolvió la contradicción de tesis 299/2013, cuyo tema central era determinar si la jurisprudencia puede ser objeto de control de constitucionalidad y/o convencionalidad ex officio, a cargo de los tribunales colegiados, cuando se detecte que resulta violatoria de algún derecho humano contenido en la Constitución Política de los Estados Unidos Mexicanos o en los tratados internacionales de los que el Estado mexicano sea parte. La decisión de la mayoría de los ministros integrantes del tribunal pleno ${ }^{1}$ determinó, esencialmente, que la jurisprudencia no puede ser objeto de ese control.

En este trabajo nos proponemos demostrar que la decisión fue equivocada, porque desconoce o desprecia claramente tres valores fundamentales: un mandato constitucional expreso, la concepción constitucional de los derechos humanos y la jerarquía y funciones del orden internacional.

A fin de estructurar este trabajo, en primer lugar, expondremos un panorama general sobre el estado actual de lo que se ha venido llamando el "nuevo paradigma de la interpretación constitucional”, que tiene como eje central la protección, defensa y garantía de los derechos humanos (apartado II). Una vez hecho lo anterior, plantearemos el dilema relativo a la posibilidad de la autorreferencia de la inaplicación (apartado III). Posteriormente, demostraremos que es posible establecer una analogía entre las normas legislativas y la jurisprudencia (apartado IV). Y, finalmente, esgrimiremos las razones que justifican la posibilidad de inaplicar la jurisprudencia (apartado V).

En el último apartado, antes de entrar en materia, presentaremos los argumentos que apoyan la tesis de la imposibilidad de inaplicación de la jurisprudencia, que llamaremos genéricamente "tesis negativa". Después expondremos nuestros argumentos a favor de la "tesis positiva". Mediante este contraste, el lector podrá apreciar que los tipos de argumentos de los que se vale tanto la tesis negativa como la positiva son del mismo género: uno

1 La decisión se tomó por mayoría de siete votos contra dos. A favor, votaron los ministros Jorge Mario Pardo Rebolledo (ponente), Arturo Zaldívar Lelo de Larrea, Luis María Aguilar Morales, Alberto Pérez Dayán, Margarita Beatriz Luna Ramos, Olga María Sánchez Cordero de García Villegas y Fernando Franco González Salas; en contra, lo hicieron los ministros José Ramón Cossío Díaz y el presidente Juan N. Silva Meza. Estuvieron ausentes los ministros Sergio A. Valls Hernández y Alfredo Gutiérrez Ortiz Mena. 
de ellos versa sobre la relación entre jurisprudencia y normas legislativas; y el otro, sobre la concepción de autoridad que importa la jurisprudencia.

\section{EL NUEVO PARADIGMA DE CONTROL CONSTITUCIONAL}

\section{Las voces de la teoría constitucional}

A partir de la Segunda Guerra Mundial, las principales corrientes teóricas conciben al Estado liberal de derecho como un Estado con una Constitución vigente que provee el diseño y organización de los poderes de un Estado; una declaración de derechos y una vocación de cambio en la forma de entender y operar con las fuentes del derecho. Se trata de un fenómeno graduable, en el que la "constitucionalización" de todos los aspectos de la vida social se va haciendo realidad a través de la resolución de los conflictos bajo la luz de los valores constitucionales. En este sentido, la Constitución se considera "invasora", es decir, capaz de condicionar tanto la legislación como la jurisprudencia y el estilo doctrinal, la acción de los actores políticos y las relaciones sociales. El fenómeno, además, puede verse como sujeto a una serie de condiciones, a saber: 1) un mínimo de rigidez constitucional; 2) la existencia de la garantía jurisdiccional de la Constitución; 3) la admisión de la fuerza vinculante de la Constitución; 4) la aceptación de que la interpretación de la Constitución sea extensiva y no restrictiva; es decir, que el paradigma interpretativo no sea la interpretación literal; 5) que la interpretación conforme sea posible; 6) que sea posible la aplicación directa de las normas constitucionales, y 7) que la Constitución influya sobre las relaciones políticas. ${ }^{2}$

En medio de este fenómeno, naturalmente, los derechos humanos ocupan la escena central. Puede decirse que en el modelo actual el énfasis está puesto en los derechos humanos más que en otros factores que en el viejo paradigma representaban auténticos baluartes: el principio de legalidad,

2 Guastini, Riccardo, “La ‘constitucionalización' del ordenamiento jurídico: el caso italiano", Estudios de teoría constitucional, trad. de José María Lujambio, México, Fontamara, 2001, pp. 154-164. Una reflexión sobre la relación entre "constitucionalismo" y "liberalismo" puede encontrarse en Cossío Díaz, José Ramón, "Liberalismo, Constitución y constitucionalismo. Los extremos de una compleja relación", en Aguilar Rivera, José Antonio (coord.), La fronda liberal. La reinvención del liberalismo en México (1990-2014), México, Taurus, 2014, pp. 219-230. 
irrestricta división de poderes, la letra de la ley como dogma, la certeza jurídica, etcétera, que desde luego no han desaparecido, pero que ya no ocupan el sitio central en las discusiones sobre derechos que surgen de los casos difíciles o trágicos, donde son, precisamente, los derechos humanos los que juegan el papel principal. ${ }^{3}$

En este sentido, es importante mencionar que si los derechos humanos ocupan este papel central, entonces, naturalmente, el operador jurídico —el juzgador - no puede seguir pensando y administrando las fuentes del derecho de forma tradicional, sino que ha de considerar que el nuevo fenómeno requiere también una nueva teorización. ${ }^{4}$ Esta nueva teorización, esta forma novedosa de aproximarse al fenómeno jurídico, es lo que constituye el llamado nuevo paradigma.

\section{Los avances jurisprudenciales en México}

De conformidad con el contenido de los artículos 1o. y 133 constitucionales, y con la interpretación que el tribunal pleno hizo en el expediente Varios 912/2010, de la sentencia de la Corte Interamericana de Derechos Humanos en el caso 12.511 Rosendo Radilla Pacheco contra los Estados Unidos Mexicanos, estamos ante un nuevo paradigma en nuestro sistema de control constitucional en el que se ha ampliado el catálogo de los derechos humanos para conformar un nuevo universo formado por los derechos reconocidos en la Constitución Política de los Estados Unidos Mexicanos, más los reconocidos por los tratados internacionales en los cuales el Estado mexicano sea parte. ${ }^{5}$

Así, el tribunal pleno estableció que el artículo 1o. de la Constitución Política de los Estados Unidos Mexicanos - reformado mediante decreto publicado en el Diario Oficial de la Federación del 10 de junio de 2011obliga a todas las autoridades del país, dentro del ámbito de sus competen-

3 Al respecto, véase Atienza, Manuel, El derecho como argumentación, Barcelona, Ariel, 2006, pp. 55 y 56; e id., "Constitución y argumentación", Anuario de Filosofía del Derecho, núm. 24, 2007, pp. 197-228.

Ibidem, p. 200.

5 Al respecto, véase Cossío Díaz, José Ramón, "Primeras implicaciones del Caso Radilla", Cuestiones Constitucionales. Revista Mexicana de Derecho Constitucional, núm. 26, junio-diciembre de 2012, pp. 31-63; Cossío Díaz, José Ramón et al., El caso Radilla. Estudio y documentos, México, Porrúa, 2013. 
cias, a velar no sólo por los derechos humanos contenidos en la Constitución federal, sino también por aquellos contenidos en los instrumentos internacionales celebrados por el Estado mexicano, adoptando la interpretación más favorable al derecho humano de que se trate, lo que se conoce en la doctrina como principio pro persona. Estos mandatos - declaró el tribunal pleno - deben interpretarse junto con lo establecido en el artículo 133 constitucional; así, se obtiene que los jueces estén obligados a preferir los derechos humanos contenidos en la Constitución y en los tratados internacionales, aun a pesar de las disposiciones en contrario que se encuentren en cualquier norma inferior. En estos casos — precisó - los jueces están obligados a dejar de aplicar las normas inferiores, y dar preferencia a las contenidas en la Constitución y en los tratados en la materia. ${ }^{6}$

Así las cosas, queda claro que los jueces (y todas las autoridades en general dentro del ámbito de sus competencias) tienen que cumplir con dos tipos de obligaciones concretas: 1) velar por los derechos humanos contenidos en la Constitución federal y en los instrumentos internacionales celebrados por el Estado mexicano, adoptando la interpretación más favorable (principio pro persona), y 2) preferir los derechos humanos contenidos en la Constitución y en los tratados internacionales, aun a pesar de las disposiciones en contrario que se encuentren en cualquier norma inferior, pudiendo en estos casos dejar de aplicar las normas inferiores y dar preferencia a las contenidas en la Constitución y en los tratados en la materia.

Para cumplir con la primera obligación, el tribunal pleno sostuvo que los jueces deberán adoptar la interpretación más favorable de acuerdo con el principio pro persona. Pero ¿qué significa esto? ¿En qué circunstancias han de optar por la interpretación más favorable para "velar" por los derechos humanos? En suma: ¿cuáles son las condiciones de aplicación de esta directiva obligatoria?

6 Lo anterior quedó manifestado en CONTROL DE CONVENCIONALIDAD EX OFFICIO EN UN MODELO DE CONTROL DIFUSO DE CONSTITUCIONALIDAD, tesis aislada P. LXVII/2011(9a.), Semanario Judicial de la Federación y su Gaceta, décima época, diciembre de 2011, t. 1, p. 535. El expediente del que derivó es Varios 912/2010. 14 de julio de 2011. Mayoría de siete votos; votaron en contra: Sergio Salvador Aguirre Anguiano, Jorge Mario Pardo Rebolledo (con salvedades), Luis María Aguilar Morales (con salvedades). Ausente y ponente: Margarita Beatriz Luna Ramos. Encargado del engrose: José Ramón Cossío Díaz. Secretarios: Raúl Manuel Mejía Garza y Laura Patricia Rojas Zamudio. 
Para responder estas interrogantes, conviene tomar en cuenta que en el aludido expediente Varios 912/2010, ${ }^{7}$ el tribunal pleno determinó que los jueces, antes de aplicar una norma jurídica, deben realizar un control ex officio, que pasa por tres momentos claramente diferenciados:

a) Una interpretación en sentido amplio del orden jurídico a la luz y conforme a los derechos humanos reconocidos en la Constitución y en los tratados internacionales en los cuales el Estado mexicano sea parte, favoreciendo en todo tiempo a las personas con la protección más amplia.

b) Una interpretación conforme en sentido estricto, que tendrá lugar cuando haya varias interpretaciones jurídicamente válidas; la misma deberá llevarse a cabo partiendo de la presunción de constitucionalidad de las leyes, y prefiriendo la interpretación que haga la ley acorde a los derechos humanos reconocidos en la Constitución y en los tratados internacionales en los que el Estado mexicano sea parte, para evitar incidir o vulnerar el contenido esencial de estos derechos, $\mathrm{y}$

c) Inaplicación de la ley, cuando las alternativas anteriores no sean posibles.

Recientemente, el tribunal pleno, al resolver la contradicción de tesis 293/2011 el 3 de septiembre de 2013, confirmó que todos los derechos humanos, con independencia de la fuente de la que provengan - constitucional o de tratados internacionales - tienen la misma jerarquía. En efecto, por mayoría de diez votos se resolvió que del artículo 1o. constitucional se desprenden un conjunto de normas de derechos humanos, de fuente tanto constitucional como convencional, que se rigen por principios interpretativos, entre los cuales no se distingue la fuente de la que derivan dichos derechos. La mayoría determinó que los derechos humanos de fuente internacional a partir de la reforma al artículo 1o. constitucional tienen la misma eficacia normativa que los previstos en la Constitución; es decir, se les reconoce el mismo rango constitucional. De esta manera, se interpretó que la reforma en materia de derechos humanos amplía el catálogo constitucional de los mismos, pues permite armonizar, a través del principio pro persona, las normas nacionales y las internacionales, garantizando así la protección más amplia a la persona. Sin embargo, y tristemente, se determinó que cuando haya una restricción expresa en la Constitución al ejercicio de los derechos humanos, se deberá estar a lo que indica la norma constitucional. Por último, se resolvió que toda la jurisprudencia de la Corte Interameri-

Idem. PASOS A SEGUIR EN EL CONTROL DE CONSTITUCIONALIDAD Y CONVENCIONALIDAD EX OFFICIO EN MATERIA DE DERECHOS HUMANOS, tesis P. LXIX/2011(9a.), p. 552. 
cana, incluyendo aquélla en los casos de litigios en los que México no fue parte, resulta vinculante para los jueces mexicanos, siempre que sea más favorable a la persona. ${ }^{8}$

\section{EL DILEMA DEL CONTROL DE CONSTITUCIONALIDAD Y/O CONVENCIONALIDAD EX OFFICIO: LA POSIBILIDAD DE LA AUTORREFERENCIA}

Ante todo este nuevo panorama, surge naturalmente la pregunta que constituye el centro de gravedad del presente asunto: ¿la obligación de ejercer el control ex officio de constitucionalidad y/o convencionalidad abarca también la jurisprudencia? Es decir: ¿las autoridades judiciales pueden cuestionar -y eventualmente inaplicar - la jurisprudencia obligatoria?

Lo anterior supone que debemos determinar si una autoridad judicial incumple con las obligaciones que imponen los artículos 1o. y 133 constitucionales cuando inaplica una jurisprudencia, no obstante que ésta es obligatoria en los términos de la Ley de Amparo, ya sea en su vigencia anterior (artículos 192 y 194 de la Ley abrogada) o en su actual vigencia (artículos 217 y 228 de la Ley vigente).

Este planteamiento no es baladí, porque de hecho representa una de las consecuencias previsibles de un nuevo modelo de control constitucional que, como se ha dicho, pone el énfasis en los derechos humanos más que en otros factores. Así, ver la producción jurisprudencial como algo incuestionable e inamovible ya no resulta acorde con el nuevo paradigma. La jurisprudencia proviene también de una autoridad que, como otras, es falible. Esas falencias, además, en tanto actos de autoridad, pueden ser violatorias de derechos humanos, por lo que la mera posibilidad de cuestionar los productos interpretativos que constituyen la jurisprudencia debe considerarse como una cuestión relevante.

Por lo demás, una posible lectura del artículo 1o. constitucional, en sus párrafos segundo y tercero, abriría la posibilidad de cuestionar la constitucionalidad y/o convencionalidad de la jurisprudencia, ya que ésta podría

8 Más adelante comentaremos este expediente y daremos cuenta de su importante relación con la contradicción de tesis que estamos tratando. Solamente conviene precisar que el ministro José Ramón Cossío Díaz votó en contra de esta contradicción de tesis 293/2011, en lo que hace a la posibilidad de que las llamadas restricciones constitucionales puedan desplazar la aplicación integral del principio pro persona. 
—no hay nada que lo impida lógicamente- incumplir con la obligación de interpretar las normas relativas a los derechos humanos de conformidad con la Constitución y con los tratados internacionales de la materia (párrafo segundo), por no favorecer, por ejemplo, la protección más amplia a las personas. Asimismo, el artículo 1o. admite una lectura según la cual las autoridades emisoras de la jurisprudencia podrían incumplir la obligación de promover, respetar, proteger y garantizar los derechos humanos de conformidad con los principios de universalidad, interdependencia, indivisibilidad y progresividad (párrafo tercero).

La jurisprudencia, por otro lado, representa una posibilidad interpretativa que no necesariamente tendría que coincidir con el propósito o finalidad del artículo 1o. constitucional, lo cual es normal, en tanto que muchos de los problemas que se resuelven mediante la jurisprudencia tienen que ver con ponderaciones entre derechos humanos, cuya resolución no suele ser pacífica. Ello, porque en este tipo de casos difíciles o trágicos, dos o más derechos humanos no pueden prevalecer al mismo tiempo y bajo las mismas circunstancias, por lo que requieren un tipo de ajuste. Ese tipo de ajuste puede revestir una buena motivación, pero también puede carecer de ella, con lo que, al menos, se abre la posibilidad de cuestionar el ejercicio interpretativo mismo.

Por otra parte, el mismo principio pro persona ofrece posibilidades interpretativas que resultan naturalmente incómodas, al menos para aquellas personas cuyos derechos humanos resultaron derrotados en la ponderación. Luego, los resultados interpretativos pueden ser perfectamente cuestionables por otro juzgador que — no lo olvidemos — también está obligado a resolver conflictos bajo la luz del principio pro persona, y que podría encontrar la jurisprudencia aplicable como violatoria de algún derecho humano.

En suma, en el momento histórico que nos encontramos en México, es posible afirmar que los juzgadores - como los tribunales colegiados contendientes - se hallan en medio de un auténtico dilema, en el que las posibles alternativas de solución se presentan, ambas, como desventajosas. En efecto, si un juzgador se encuentra obligado por el artículo 1o. a ser congruente con el nuevo paradigma, para actuar en consecuencia debe sortear varios obstáculos que el propio sistema jurídico ofrece, porque proviene de un paradigma anterior. Así, para tener éxito en la consecución del nuevo paradigma se verá obligado a no atender a diversas exigencias del sistema, tales como la obligatoriedad irrestricta de la jurisprudencia. Y, por otro lado, 
si este jurista asume que los pilares del sistema - como la jurisprudenciano pueden ser siquiera cuestionados, porque en ello puede ir la subsistencia del propio sistema, entonces no tiene otra opción que ignorar el nuevo paradigma, y así seguir resolviendo los conflictos a la manera tradicional. Por eso se trata de un genuino dilema, ya que las posibles soluciones resultan, como se señaló, desventajosa para el juzgador.

En el siguiente apartado abordaremos este problema a partir de la posibilidad de establecer una analogía entre las normas de fuente legislativa y la jurisprudencia.

\section{IV. ¿ES POSIBLE PLANTEAR UNA ANALOGÍA ENTRE UNA NORMA DE FUENTE LEGISLATIVA Y UNA JURISPRUDENCIA?}

No debe perderse de vista - como se determinó en el expediente Varios 912/2010 - que el objeto de control de constitucionalidad y/o convencionalidad (difuso y concentrado) son inequívocamente las normas jurídicas o, más exactamente, las disposiciones jurídicas. Claramente una jurisprudencia no es exactamente igual a una norma jurídica, pero lo relevante aquí no es esa distinción meramente formal, sino determinar si las disposiciones jurídicas y la jurisprudencia comparten la misma base epistémica que puede dar lugar a la inaplicación. Para ello, es necesario establecer si disposiciones y jurisprudencia son o no analogables. Exploremos, pues, esta posibilidad, a partir de un posible argumento analógico.

En primer término, conviene señalar que el concepto de analogía no es un concepto unívoco, sino que admite, por lo menos, tres significados diferentes: 1) como proporción; es decir, como semejanza de relaciones; 2) como argumento que permite pasar de lo particular a lo particular, y finalmente, 3) como atributo que se predica de ciertos conceptos llamados imprecisos, borrosos o vagos; esto es, la analogía como relación de semejanza. ${ }^{9}$

La segunda acepción es la utilizada por los juristas $\mathrm{y}$, por ende, de la que se ocupa este estudio. El concepto de analogía jurídica puede definirse de la siguiente manera: se trata de un argumento interpretativo mediante el cual se justifica trasladar la solución legalmente prevista para un caso,

9 Atienza, Manuel, "Algunas tesis sobre la analogía en el derecho", Doxa. Cuadernos de Filosofía del Derecho, Alicante, núm. 2, 1985, pp. 223-229. 
a otro caso distinto, no regulado por el ordenamiento jurídico, pero que es semejante al primero. ${ }^{10}$

Puede decirse que en todo argumento analógico nos encontramos con cuatro elementos:

a) Una norma $(\mathrm{N})$ que regula un supuesto $(\mathrm{S} 1)$ al que aplica la consecuencia jurídica $(\mathrm{C})$;

b) Otro supuesto (S2) no regulado por ninguna norma;

c) Los supuestos $\mathrm{S} 1$ y S2 son semejantes, $\mathrm{y}$

d) Entre los supuestos S1 y S2 se aprecia identidad de razón.

Una vez que confluyen tales elementos, por medio del argumento analógico, se justifica la aplicación de la consecuencia $\mathrm{C}$ también al supuesto S2.

En nuestro problema a resolver, contamos con todos estos elementos, ya que, en primer lugar, tenemos una norma $(\mathrm{N})$ contenida en los artículos 10. y 133 constitucionales, que regula un supuesto (S1) relativo a la existencia de normas jurídicas que resulten violatorias de algún derecho humano contenido en la Constitución Política de los Estados Unidos Mexicanos o en los tratados internacionales de los que el Estado mexicano sea parte, al que es posible aplicar una consecuencia jurídica (C); a saber: la inaplicación de la norma referida. Nuestra norma $(\mathrm{N})$ podría ser traducida en estos términos: Todos los jueces del país tienen la facultad de inaplicar cualquier norma jurídica que, a su juicio, sea violatoria de algún derecho humano contenido en la Constitución Política de los Estados Unidos Mexicanos o en los tratados internacionales de los que el Estado mexicano sea parte.

Por otra parte, tenemos un segundo supuesto (S2) no regulado; una auténtica laguna, que constituye, precisamente, el tema central de la contradicción de tesis 299/2013: ¿Es posible inaplicar cualquier jurisprudencia que, a juicio del juzgador, sea violatoria de algún derecho humano contenido en la Constitución Política de los Estados Unidos Mexicanos o en los tratados internacionales de los que el Estado mexicano sea parte?

Finalmente, los supuestos S1 y S2, además de ser claramente semejantes (ambos son utilizados por los jueces como fundamento para resolver conflictos jurídicos, con fuerza vinculante y provenientes de una autoridad), son susceptibles de ser analizados bajo una idea de identidad de razones, que

10 Ezquiaga, Francisco Javier, “Argumentos interpretativos y postulado del legislador racional”, Isonomía, México, núm. 1, octubre de 1994, pp. 69-98. 
se verá a continuación. En el apartado siguiente se esgrimirán las razones que justifican esta analogía.

Por las razones anteriores, la pregunta que encabeza este subapartado debe responderse en sentido afirmativo, pues se reúnen todas las condiciones para establecer una posible analogía entre normas de cuño legislativo y jurisprudencia. El paso siguiente consistirá en justificar la analogía mediante un desarrollo de las razones de identidad entre los elementos que se presentan como análogos.

\section{RAZONES QUE JUSTIFICAN LA POSIBILIDAD \\ DE INAPLICAR LA JURISPRUDENCIA}

A fin de presentar nuestros argumentos a favor de la inaplicación de la jurisprudencia, presentaremos en primer lugar algunos argumentos en contra, que hemos recogido de la opinión de algunos de los ministros que integraron la mayoría del tribunal pleno, en las sesiones celebradas el 13 y 14 de octubre de 2014. A ese apartado le llamaremos "tesis negativa". Posteriormente, expondremos nuestros argumentos en varios subapartados que conformarán la "tesis positiva".

\section{La tesis negativa}

Los siguientes son algunos de los argumentos que apoyan la tesis negativa, y que pudimos identificar y aislar en la discusión del asunto el 13 y 14 de octubre de 2014, en el pleno de la Suprema Corte de Justicia de la Nación.

\section{A. La jurisprudencia no puede equipararse con una norma}

De conformidad con este argumento, la jurisprudencia no puede ser identificada como una norma jurídica, porque ésta es un enunciado normativo legislado, y la jurisprudencia, en cambio, supone un criterio interpretativo de algún enunciado normativo legislado. Así, dado que la ley y la jurisprudencia tienen medios distintos de creación y modificación, no pueden ser consideradas como semejantes o análogas.

Por otra parte, las cualidades de la jurisprudencia no son exactamente coincidentes con todas las cualidades de la ley, porque la primera resulta 
de una sentencia en la que se establece un criterio de interpretación, y el tribunal que la emite no goza de la libertad de configuración que tiene el legislador para emitir la ley. La jurisprudencia, por otro lado, no es aplicable a todas las personas, porque solamente está dirigida a aquellos tribunales que están obligados a acatarla.

Finalmente, si se estableciera que la jurisprudencia de la Corte es inconvencional, ello implicaría que para el juzgador el criterio contenido en ella es contrario a los derechos humanos previstos en los tratados internacionales de los que el Estado mexicano es parte y, consecuentemente, el juzgador dejaría de aplicarla; sin embargo, con esta forma de proceder, considero que el control de convencionalidad estaría incompleto, porque subsistiría en su plenitud el artículo 217 de la Ley de Amparo; es decir, la norma que determina la obligatoriedad de la jurisprudencia, y lo hace sin distinción.

\section{B. La jurisprudencia puede asimilarse a una norma, pero el medio para controlarla no puede ser el control difuso, sino la sustitución}

La jurisprudencia puede ser considerada como una norma en todos los sentidos, empezando por su fuerza obligatoria; sin embargo, para controlar la regularidad de constitucionalidad o convencionalidad de la jurisprudencia existen medios previstos en el sistema, tales como la sustitución en la Ley de Amparo.

De este modo, se acepta la tesis de la inaplicación, pero se niega que se pueda hacer mediante el control difuso o cualquier otro medio que no sea el procedimiento específico que para ello ha dispuesto el legislador. De este modo, son los ministros de la Suprema Corte - y sólo ellos - los que pueden llegar a controlar la regularidad de la jurisprudencia, y, de este modo, expulsar, mediante la sustitución, aquella que pudiera resultar violatoria de los derechos humanos de fuente constitucional o convencional.

\section{La obligatoriedad de la jurisprudencia es irrestricta}

Una tesis más es aquella mediante la cual se sostiene que los ejercicios de interpretación judicial han de estar gobernados por competencias que darán orden y coherencia a las interpretaciones que se realicen sobre los 
derechos humanos; es decir, que por razones de autoridad no es posible inaplicar los criterios jurisprudenciales, porque éstos implican un criterio de autoridad que ha de imponerse a cualquier otra interpretación, hasta en tanto no se invalide tal criterio por un determinado órgano con suficiente jerarquía en la estructura competencial del Poder Judicial. ${ }^{11}$

Este argumento es parecido al anterior, pero el énfasis lo coloca en la idea de autoridad: dado que la jurisprudencia es un criterio jerárquicamente superior a cualquier otro, entonces sólo podría ser cuestionado por un ente que tuviera la competencia para revisarlo; como no existe tal ente, entonces la cabeza de órgano es la única facultada para cuestionar la obra jurisprudencial, mediante los medios que el propio sistema dispone para ello.

\section{La posibilidad de transgredir el sistema de jurisprudencia}

Otro posible argumento derivado de esta tesis negativa es aceptar que no es posible inaplicar la jurisprudencia porque con ello se podría transgredir el sistema relativo a su obligatoriedad, dispuesto en los artículos 94, párrafo octavo, de la Constitución Política de los Estados Unidos Mexicanos, y 217 de la Ley de Amparo vigente.

Para quienes sostienen este argumento, si se admitiera la posibilidad de hacer un control de convencionalidad sobre una jurisprudencia, ello implicaría la inobservancia de las normas anteriormente señaladas, las cuales no habrían sido previamente analizadas ni declaradas inconstitucionales, ni inconvencionales y, por lo tanto, una interpretación de esa naturaleza no podría realizarse si no es desvirtuado, o prácticamente anulando, todo el sistema de creación jurisprudencial. Así, se podría incurrir en una contradicción normativa que no se actualiza cuando el control de convencionalidad se hace exclusivamente sobre preceptos legales o reglamentarios.

\section{E. La confianza garantizada (infalibilidad)}

El último argumento detectado consiste en admitir que la imposibilidad de inaplicación de la jurisprudencia por los tribunales colegiados no debe generar ningún tipo de preocupación, porque la jurisprudencia constituye un

11 Para profundizar sobre los sistemas de precedentes, véase Cossío Díaz, José Ramón, La controversia constitucional, México, Porrúa, 2008, pp. 698-717. 
criterio revisado por la más alta esfera competencial, que blinda al criterio de cualquier posible error.

La jurisprudencia — sostienen los defensores de esta tesis - ya supone que un órgano terminal, superior al órgano que pretende inaplicarla, reflexionó el tema y lo definió en todos sus alcances, lo cual, incluso, lleva implícito el que ese tribunal reflexionó sobre la conformidad convencional de esa norma y, en esa medida es que adoptó una decisión que le parece unificadora y, por ser órgano terminal, obligatoria.

Así, un juzgador puede inaplicar una ley por ser convencional, precisamente porque no hay un pronunciamiento anterior de carácter obligatorio, de un órgano terminal que le oriente en otro sentido; pero la jurisprudencia es una reflexión interpretativa que ya pasó por un proceso intelectivo en el que se comparó una norma con el orden jurídico y que llevó al intérprete a decidir el significado del enunciado, buscando con ello orientar a los jueces inferiores a que, sobre esa base, resuelvan las controversias que se les presenten. Por ello, no pueden —ni deben-juzgar la interpretación y mucho menos inaplicarla.

\section{La tesis positiva y los argumentos que derrotan a la tesis negativa}

La tesis positiva, que busca justificar la facultad de inaplicar la jurisprudencia, supone la negación de los argumentos en que se basa la tesis negativa, los cuales descansan en dos pilares esenciales: negar que la jurisprudencia sea una norma y el énfasis en el concepto de autoridad.

Esta tesis positiva pretende mostrar, por un lado, que los criterios jurisprudenciales, si bien es cierto que tienen una fuente distinta a la de las normas (pues son creadas a partir de un procedimiento judicial y no legislativo), en realidad, son normas (tal como son normas también aquellas interpretaciones, hechas por cualquier persona, que asignan correctamente un significado a un enunciado normativo). Y, por otro lado, la tesis positiva niega que sea relevante la razón de autoridad que supone la existencia de un modo rígido de competencias para derrotar o inaplicar cierto tipo de criterios jurisprudenciales. Por el contrario, la tesis positiva parte de las mismas razones por las cuales se acepta como justificada la inaplicación de normas internas por inconvencionalidad o inconstitucionalidad, las cuales tienen que ver con un entendimiento de los derechos humanos como razón pública universal que se resiste a una acotación competencial, basada en 
una idea de autoridad, que impida, en principio, la argumentación de todo aquel — autoridad o persona - que al tomar sus decisiones quiera razonarlas y justificarlas con base en los derechos humanos.

\section{A. Primer argumento: distinguir entre enunciado o disposición y norma}

El primer argumento de la tesis positiva parte de la distinción entre enunciados o disposiciones normativas y normas. ${ }^{12}$ Los enunciados normativos son los que acuerda el legislador y expresa en un texto legal. Las normas, por otro lado, son el significado que está justificado atribuir a tales enunciados normativos - a veces, el significado de un enunciado normativo no supone problema alguno, pero en otros casos es necesario realizar ejercicios elaborados de interpretación para determinar el significado normativo de un enunciado normativo- - Es el significado de tales enunciados lo que tiene un carácter esencialmente normativo; es decir, como razón para actuar conforme a lo prescrito en un enunciado normativo.

Si se tiene en cuenta esta distinción, entonces, en realidad los criterios jurisprudenciales no son otra cosa que normas, porque es precisamente a través de esos criterios jurisprudenciales que se le atribuye un significado a algún enunciado normativo. A través del proceso judicial de creación de jurisprudencia se determinan las normas del sistema jurídico en aquellos casos en que haya dudas sobre el significado de algún enunciado normativo. No debe llegarse al extremo de entender, a partir de lo anterior, que sólo hay normas si hay jurisprudencia. Lo que sucede en el sistema jurídico es que hay ejercicios constantes de asignación de significado a ciertos enunciados normativos, los cuales son realizados por los operadores jurídicos, cualquiera de ellos: autoridades, litigantes y personas. Estos ejercicios de asignación de significado a los enunciados normativos — que pueden denominarse ejercicios de interpretación - la mayoría de las veces tienen el objetivo de asignar el significado que ante un caso concreto tiene cierto enunciado

12 Con respecto a la distinción entre enunciados normativos y normas, véase Guastini, Riccardo, Estudios sobre la interpretación jurídica, trad. de Marina Gascón y Miguel Carbonell, México, UNAM, Instituto de Investigaciones Jurídicas, 1999, pp. 10 y 11; Alchourrón, Carlos E. y Bulygin, Eugenio, "Norma jurídica”, Enciclopedia iberoamericana de filosofia, vol. 11: El derecho y la justicia, Madrid, Trotta, 1996, pp. 133-147; Dworkin, Ronald, El imperio de la justicia, trad. de Claudia Ferrari, Barcelona, Gedisa, 1997. 
normativo, pero también, en otros casos, tales ejercicios de asignación de significado se plantean en abstracto; es decir, se busca determinar cuál es el significado normativo de un enunciado normativo con independencia de cualquier caso concreto.

Es importante no perder de vista que para atribuir un significado a un enunciado normativo $\mathrm{X}$ es preciso realizar una interpretación que tome en cuenta un enunciado normativo Y como parámetro para atribuir el significado al enunciado X. Así, cuando se utiliza como parámetro para la interpretación, por ejemplo, el enunciado normativo de derecho humano Y, convencional o constitucional, entonces este enunciado es el marco de referencia para interpretar el enunciado normativo X. Lo importante es advertir que el enunciado de derecho humano Y requiere también una asignación de significado a través de un ejercicio de interpretación para que funcione genuinamente como parámetro.

A partir de lo anterior, es posible concluir que en cualquier ejercicio de interpretación se distinguen dos etapas: 1) la asignación de significado a la norma que funcionará como parámetro, y 2) la asignación de significado al enunciado a interpretar. Es importante tener presente que cuando un criterio jurisprudencial se vale de un enunciado de derecho humano como parámetro o marco de referencia para interpretar otro enunciado - por ejemplo, uno dispuesto en alguna ley-, entonces es obvio que la interpretación del enunciado de derecho humano no implica otro enunciado como marco de referencia, pues es un enunciado que conforma el techo o bóveda del sistema jurídico, sino que, ante ello, el operador jurídico ha de reflexionar con la finalidad de atribuirle a tal enunciado de derecho humano el mejor significado posible. $\mathrm{Y}$ es este significado atribuido al enunciado del derecho humano en cuestión lo que constituye propiamente la norma de derecho humano.

Tener en cuenta la fenomenología de la interpretación que se ha apuntado ayuda a reforzar la tesis de que los jueces tienen permitido inaplicar los criterios jurisprudenciales. Esto es así porque tales criterios constituyen la explicitación de normas, no sólo de normas legales (producto de la asignación de significado a un enunciado base), sino también de normas propiamente constitucionales (producto de la asignación de significado a un enunciado marco, como lo puede ser una disposición constitucional o convencional de derecho humano). De este modo, es posible afirmar que la apertura en el acceso a la interpretación de los derechos humanos constitucionales y convencionales está justificada a partir de tener en cuenta esta fenomeno- 
logía de la interpretación, pues así es posible reconocer que no puede haber interpretaciones de los enunciados del sistema jurídico que sean coherentes con los principios del sistema — con los derechos humanos — si no se admite que para tener decisiones coherentes es indispensable, e inevitable, que se interpreten también los enunciados techo o bóveda del sistema, como son los derechos humanos.

\section{B. Segundo argumento: la superioridad epistémica}

El segundo argumento de la tesis positiva, por un lado, parte del argumento anterior y, por otro, se relaciona esencialmente con el argumento que justifica la facultad de inaplicar normas internas. Si los criterios jurisprudenciales son normas porque importan precisamente la asignación de significado a cierto enunciado jurídico, entonces tales normas jurisprudenciales (si se permite la expresión) pueden inaplicarse como cualquier otra norma de fuente estrictamente legislativa.

Para negar lo anterior es indispensable que se restrinja la facultad de inaplicación a ciertos órganos, y eso importaría establecer una barrera competencial. Y si tal barrera competencial se impone para impedir que ciertos órganos puedan fundamentar sus decisiones en consideraciones que tomen en cuenta los derechos, entonces tal barrera competencial no puede justificarse a la luz de los derechos, pues con ello se negaría que éstos puedan ser comprendidos y accesibles a toda persona que esté dispuesta a ofrecer argumentos razonables al respecto y, además, se estaría asumiendo que sólo ciertos órganos cuentan con la capacidad suficiente para argumentar sobre lo que exigen los derechos, y ello, francamente, no es otra cosa que asumir una superioridad epistémica omnicomprensiva y excluyente, que contradice la idea misma de los derechos humanos.

Si a un órgano no le está permitido justificar su decisión a la luz de algún derecho y, en consecuencia, no le está permitido decidir inaplicar cualquier norma (de fuente legislativa o jurisprudencial) por considerarla inconstitucional o inconvencional, entonces, a falta de una buena razón que justifique tal restricción, se estaría asumiendo, de antemano, la incapacidad de tal órgano para argumentar correctamente sobre lo que exigen los derechos. Y una presuposición como la anterior negaría que tal persona — la persona o personas que integran algún órgano - es lo suficientemente capaz como para razonar con los derechos; y esta presuposición a su vez negaría el ori- 
gen mismo de los derechos en el derecho, que no están ahí porque un grupo de superdotados intelectualmente así lo han querido, sino porque cualquier persona puede ver en ellos, en los derechos, una exigencia de moralidad pública $^{13}$ para tenerlos; esta idea de poder ver en los derechos exigencias de moralidad pública constituye la idea básica de los derechos entendidos como entidades de razón pública sobre los que cualquiera puede opinar y orientar su decisión de acuerdo con lo que ellos, los derechos, exigen a partir de su mejor entendimiento.

Por lo demás, no podemos admitir que la Suprema Corte de Justicia de la Nación sea impermeable al principio pro persona, contenido en el artículo 1o. de la Constitución Política de los Estados Unidos Mexicanos. Dicho principio está dirigido, sin excepción, a todas las autoridades (especialmente las judiciales) del país, y las habilita o faculta a llevar a cabo el consabido control difuso de la regularidad constitucional. ¿Por qué la Suprema Corte podría escapar de ese control? Insistimos: salvo que se la crea epistémicamente superior o que se admita que su jurisprudencia es infalible, no vemos ninguna razón válida que permita pensar en que la Corte está exenta del principio pro persona. Si se admite esa exención, entonces se estaría aceptando implícitamente que la Corte sencillamente no puede violar derechos humanos mediante sus criterios (es, pues, infalible en ese aspecto), o bien que, aunque se admitiera que pudiera violarlos, no son los jueces ordinarios quienes puedan advertirlo y resolverlo, sino ella misma a través de los medios previstos en el sistema, como el de la sustitución de la jurisprudencia, según se pregona en la tesis negativa.

Ninguno de estos dos escenarios es constitucionalmente admisible, pues ni los ministros son infalibles $-\mathrm{y}$ nada extraordinario hay en ello- - , ni podemos consentir una actitud de soberbia institucional al considerar que la Corte sólo se corrige a sí misma, ya que ello implicaría desconocer el alcance del principio pro persona.

\section{Tercer argumento: el sistema de revisión es compatible con la inaplicación}

Amén de los argumentos dados para justificar la facultad de inaplicar la jurisprudencia inconvencional o inconstitucional, queda por dilucidar un

13 Se puede decir que los derechos representan una exigencia de moral pública porque prescriben un trato (moralmente justificado) entre las personas y la autoridad en el ámbito de los intereses de la vida en comunidad; esto es, lo público. 
punto incómodo: el que se refiere al diseño institucional de la revisión del ejercicio de la facultad de inaplicar la jurisprudencia. Como hemos dicho, de acuerdo con la tesis positiva no es posible limitar de antemano el pronunciamiento de una decisión con base en derechos, a menos que se niegue el carácter accesible de los derechos, por constituir entidades de razón pública universal; sin embargo, las decisiones al respecto pueden ser sometidas a revisión por algún órgano y, necesariamente, en algún momento debe haber una decisión final al respecto. Al igual que sucede con las normas legislativas, la revisión de las inaplicaciones de la jurisprudencia obedecerían a la lógica de los propios medios de impugnación del sistema, tanto ordinarios como de control constitucional. Esto quiere decir que eventualmente los propios órganos emisores de la jurisprudencia inaplicada podrían revisar ese ejercicio de inaplicación. Consecuentemente, a fin de que no se incurriera en un mero juego circular, tendría que diseñarse un sistema escalonado de revisión en el que el revisor de la inaplicación fuera siempre un órgano jerárquicamente superior, con lo cual se reduciría considerablemente esa circularidad. El único órgano que no podría, lógicamente, estar sujeto a revisión sería el tribunal pleno, por lo que podría revisar la inaplicación de sus tesis de jurisprudencia. Sin embargo, aun en este caso, la revisión tendría algún sentido, puesto que la conformación del tribunal pleno está en constante transformación, por lo que cabría la posibilidad de que una nueva conformación analizara la impugnación de la eventual inaplicación de la jurisprudencia.

Existe otra razón para justificar la existencia de la analogía entre una norma legislativa y una jurisprudencia, relacionada también con la posibilidad de revisión de la inaplicación. Un juzgador que inaplicara la jurisprudencia por considerarla inconstitucional o inconvencional estaría haciendo un juicio a un criterio interpretativo, que no es otra cosa que el contenido (ya extraído, ya explicitado) de una disposición jurídica o enunciado normativo. Naturalmente, para llegar a esa conclusión, ese juez debió haber realizado, a su vez, un esfuerzo interpretativo. Así las cosas, tiene sentido preguntarnos: ¿puede interpretarse una interpretación? La respuesta es afirmativa, ya que en el nuevo paradigma cobra sentido una concepción de la interpretación no formalista, en la que más que "descubrir" un significado oculto en la disposición que se interpreta (que puede ser calificado de falso o verdadero, como sucede en la vocación formalista) se admite la posibilidad de "atribución", "creación" o "asignación" del significado mismo, siempre que 
exista una adecuada motivación. De este modo, todas las interpretaciones son cuestionables, precisamente, porque no se consideran falsas o verdaderas, sino razonables, justas o más acordes con el principio pro persona. ${ }^{14}$ Así, no parecería insensato que un juez o tribunal colegiado apreciara que una determinada jurisprudencia estuviera adoptando una interpretación restrictiva o, incluso, lesiva de derechos humanos digna de ser inaplicada.

No pasa inadvertido que para que sea posible la revisión de la inaplicación de la jurisprudencia es indispensable que existan normas de competencia que habiliten a determinados órganos a llevar a cabo esa revisión, con lo que podría argumentarse que la tesis positiva se contradice al afirmar que en la argumentación de los derechos humanos no deberían admitirse restricciones competenciales. Para diluir la contradicción es importante tener en cuenta que no es que los derechos humanos se resistan a que la argumentación sobre ellos se encuentre acotada por reglas competenciales; más bien se resisten a que esté restringida, de antemano, la posibilidad de que los jueces tomen y argumenten sus decisiones con base en tales derechos, sin ofrecer alguna razón adicional.

Los derechos humanos, como razón pública universal, no se oponen a que las decisiones que los involucran — por ejemplo, la decisión de inaplicar una norma jurisprudencial por ser contraria a ellos - estén sujetas a revisión, de acuerdo con un sistema que prevea, como no podría ser de otro modo, las competencias que tendrán ciertos órganos, y sólo ellos, para revisar las eventuales inaplicaciones. Lo que estaría injustificado, se insiste, es que el sistema de competencias partiera de un elitismo intelectual atribuido a los órganos encargados de realizar la revisión. Dicho de otro modo, los derechos humanos encuentran armonía con un sistema de revisión basado en competencias si este sistema está justificado. Esa justificación depende de que tal sistema de revisión suponga la maximización de las decisiones correctas sobre algún área del derecho; es decir, el sistema de revisión está justificado sólo si a través de él es probable que el número de decisiones correctas que se tomen —el número de inaplicaciones jurisprudenciales - sea mayor que el número de decisiones correctas que habría en la hipótesis de que no existiera tal sistema de revisión. La maximización de las decisiones correctas dependerá de un escenario institucional apropiado para la toma de

14 Sobre las teorías de la interpretación, véase Lifante, Isabel, La interpretación jurídica en la teoría contemporánea del derecho, Madrid, Centro de Estudios Políticos y Constitucionales, 1999; Guastini, Riccardo, Estudios sobre la interpretación..., cit. 
decisiones que propicien el diálogo, la pluralidad de puntos de vista y, en general, la deliberación razonable de cara a construir el consenso necesario para tomar decisiones correctas. El sistema escalonado de revisión con el que cuenta nuestro sistema jurídico, concretamente, el sistema de control concentrado, parece cumplir con estas exigencias.

D. Cuarto argumento: respeto a los principios de consistencia y coherencia con relación al derecho internacional de los derechos humanos

No haremos aquí un repaso de los más recientes avances legislativos y jurisprudenciales del Estado mexicano en materia de derechos humanos, pero sí vale la pena mencionar que la Suprema Corte no ha sabido reaccionar adecuadamente ante el nuevo paradigma.

Sin duda, uno de los precedentes más importantes que representan esta realidad es la contradicción de tesis 293/2011, resuelta por el tribunal pleno de la Suprema Corte el 3 de septiembre de 2013. En ella, se reconoce que la interpretación de las normas del sistema jurídico, tanto de las normas ordinarias como constitucionales y convencionales, y la facultad de inaplicarlas cuando estas sean contrarias a los derechos humanos de fuente constitucional o convencional, encuentra un límite en las restricciones a los derechos humanos constitucionalmente expresas. De este modo, cuando un operador jurídico esté frente a una restricción constitucional a un derecho humano, ha de entender que tal disposición es de observancia estricta y, por tanto, no podrán dejar de aplicarla por más que considere que es contraria a los derechos humanos.

El anterior argumento constituye, desde nuestro punto de vista, un auténtico disparate jurídico, porque implica desconocer el mandato constitucional expreso en el artículo 1o. constitucional, mediante una estratagema en la que se sobredimensionó la expresión "cuyo ejercicio no podrá restringirse ni suspenderse, salvo en los casos y bajo las condiciones que esta Constitución establece". En efecto, la mayoría no consideró que esa frase también deba entenderse bajo la clave interpretativa del principio pro persona, por lo que debe ser entendida única y exclusivamente con respecto a las condiciones establecidas en varios párrafos del artículo 29 de la propia Constitución. ${ }^{15}$

15 Al respecto, véase Cossío Díaz, José Ramón, "Las trampas del consenso", Nexos, 1o. de octubre de 2013. 
En esta línea de pensamiento, no podemos entender de dónde se extrae el criterio de intangibilidad de una norma cuya jerarquía formal es inferior aun con respecto a las normas emitidas por el legislador. De este modo, la resolución de la contradicción de tesis 299/2013 — de la que surge este análisis - incurre en una insalvable contradicción entre la tesis de la imposibilidad de inaplicación de la jurisprudencia y lo afirmado en el segundo párrafo de la página 59 de la referida CT 293/2011, que dice lo siguiente:

no debe entenderse el carácter vinculante de los criterios interamericanos en un sentido fuerte, es decir, como un lineamiento que constriña a los jueces internos a resolver aplicando indefectiblemente el estándar sentado por la Corte Interamericana, pasando por alto, incluso, los precedentes del Poder Judicial de la Federación. Por el contrario, esta obligatoriedad debe entenderse como una vinculación a los operadores jurídicos internos a observar en sus resoluciones un estándar mínimo, que bien podría ser el interamericano o el nacional, dependiendo cuál sea el más favorable a las personas. En todo caso, lo importante será que la inaplicación de un criterio jurisprudencial, nacional o interamericano, se justifique atendiendo a la aplicación de otro que resulte más favorecedor a la persona.

Vale la pena recordar que, con relación al control de convencionalidad, la Corte Interamericana de Derechos Humanos ha expuesto en su jurisprudencia reiterada que cuando un Estado es parte de un tratado internacional como la Convención Americana, todos sus órganos -incluidos sus jueces- están sometidos a aquél. Ello los obliga a velar por que los efectos de las disposiciones de la Convención no se vean mermadas por la aplicación de normas contrarias a su objeto y fin, por lo que los jueces y órganos vinculados a la administración de justicia — como el Ministerio Público-, en todos los niveles, tiene la obligación de ejercer ex officio un control de convencionalidad entre las normas internas y la Convención Americana, en el marco de sus respectivas competencias y de las regulaciones procesales correspondientes. En esta tarea, deben tener en cuenta no sólo el tratado, sino también la interpretación que del mismo ha hecho la Corte Interamericana, intérprete última del Pacto de San José de Costa Rica. ${ }^{16}$

16 Caso Almonacid Arellano y otros vs. Chile, sentencia del 26 de septiembre de 2006 (excepciones preliminares, fondo, reparaciones y costas), párr. 124; caso Trabajadores Cesados del Congreso (Aguado Alfaro y otros) vs. Perú, sentencia del 24 de noviembre de 2006 (excepciones preliminares, fondo, reparaciones y costas), párr. 128; caso Radilla 
Debemos subrayar que con la posibilidad de inaplicación de la jurisprudencia, no se pretende en ningún momento que los tribunales no tengan la carga argumentativa de justificación previa a la inaplicación, así como seguir los pasos establecidos en el expediente Varios 912/2010, para respetar la presunción de constitucionalidad de la misma jurisprudencia.

\section{E. Quinto argumento: la salvaguarda del sistema de la jurisprudencia}

Es importante no dejar de referirse a uno de los argumentos de la tesis negativa: que la inaplicación de la jurisprudencia tendría como efecto la transgresión del sistema relativo a su obligatoriedad, dispuesto en los artículos 94, párrafo octavo, de la Constitución Política de los Estados Unidos Mexicanos, y 217 de la Ley de Amparo vigente.

Sólo puede aceptarse este argumento si a su vez se incurre en una confusión al equiparar los efectos de una inaplicación con los efectos de una interrupción general de la obligatoriedad de la jurisprudencia, lo cual no debe ocurrir. Para no incurrir en esta confusión es indispensable realizar algunas precisiones. El efecto que aquí se propone que tenga la inaplicación de la jurisprudencia es únicamente el de no aplicarla en un caso concreto, no el de interrumpir su obligatoriedad de manera general. Ambos mecanismos son perfectamente compatibles, ya que una jurisprudencia puede ser obligatoria a pesar de que en ciertos casos, por resultar inconvencional o inconstitucional, pueda no aplicarse, si así lo considera un órgano judicial competente para ello, y esta inaplicación puede al final considerarse correcta o incorrecta por el órgano de revisión competente. Pero una jurisprudencia obligatoria puede dejar de serlo de manera general si se sigue para ello el procedimiento de sustitución, establecido en el artículo 230 de la Ley de Amparo vigente.

Pacheco vs. Estados Unidos Mexicanos, sentencia del 23 de noviembre de 2009 (excepciones preliminares, fondo, reparaciones y costas), párr. 339; caso Gelman vs. Uruguay, sentencia del 24 de febrero de 2011 (fondo y reparaciones), párr. 193; caso López Mendoza vs. Venezuela, sentencia de 1 de septiembre de 2011 (fondo, reparaciones y costas), párr. 228; caso Furlán y Familiares vs. Argentina, sentencia del 31 de agosto de 2012 (excepciones preliminares, fondo, reparaciones y costas), párrs. 303 y 305; caso Masacres de El Mozote y lugares aledaños vs. El Salvador, sentencia del 25 de octubre de 2012 (fondo, reparaciones y costas), párr. 318 y caso Gudiel Álvarez (Diario Militar) vs. Guatemala, sentencia del 20 de noviembre de 2012 (fondo, reparaciones y costas), párr. 330 , entre otros casos. 
Esto mismo sucede con cualquier norma, la cual puede resultar que no se aplique ante un caso concreto por razones relacionadas con la inconstitucionalidad o inconvencionalidad de la solución jurídica que ofrecen a un caso concreto, sin que con ello se afecte su validez, u obligatoriedad, pues para declararla inválida, para expulsarla del ordenamiento jurídico, ha de utilizarse el procedimiento establecido en el artículo 105 constitucional (concretamente, la acción de inconstitucionalidad, o bien el establecido en el artículo 107, fracción II, párrafo tercero, relativo a la declaratoria general de inconstitucionalidad). De modo que no hay razón para suponer que sobre la jurisprudencia, en tanto norma, por las razones que se han expuesto, quepa asumir que no es posible distinguir entre decisiones que afectan la aplicación ante un caso concreto y entre decisiones que afectan la validez $\mathrm{u}$ obligatoriedad general.

Ahora bien, ¿podría considerarse la inaplicación como una conducta irregular del juzgador? ¿Cuáles serían las consecuencias jurídicas para el órgano que inaplicara una jurisprudencia obligatoria? Al respecto, conviene tomar en cuenta que el artículo 217 de la Ley de Amparo vigente ${ }^{17}$ no establece ninguna sanción para quien incumpla la obligación ahí contenida. Tampoco se advierte ningún tipo de consecuencia en la Ley Orgánica del Poder Judicial de la Federación con relación a este problema concreto. Incluso, si se revisa el artículo 131 de esa ley, relativo a las causas de responsabilidad de los servidores públicos, no se advierte ningún supuesto jurídico relacionado con la inobservancia de la obligación referida en el artículo antes citado. ${ }^{18}$

17 Artículo 217. La jurisprudencia que establezca la Suprema Corte de Justicia de la Nación, funcionando en pleno o en salas, es obligatoria para éstas tratándose de la que decrete el pleno, y además para los plenos de circuito, los tribunales colegiados y unitarios de circuito, los juzgados de distrito, tribunales militares y judiciales del orden común de los Estados y del Distrito Federal, y tribunales administrativos y del trabajo, locales o federales./ La jurisprudencia que establezcan los plenos de circuito es obligatoria para los tribunales colegiados y unitarios de circuito, los juzgados de distrito, tribunales militares y judiciales del orden común de las entidades federativas y tribunales administrativos y del trabajo, locales o federales que se ubiquen dentro del circuito correspondiente./ La jurisprudencia que establezcan los tribunales colegiados de circuito es obligatoria para los órganos mencionados en el párrafo anterior, con excepción de los plenos de circuito y de los demás tribunales colegiados de circuito./ La jurisprudencia en ningún caso tendrá efecto retroactivo en perjuicio de persona alguna.

18 Artículo 131. Serán causas de responsabilidad para los servidores públicos del Poder Judicial de la Federación:/ I. Realizar conductas que atenten contra la independencia de la función judicial, tales como aceptar o ejercer consignas, presiones, encargos o comisiones, o cualquier acción que genere o implique subordinación respecto de alguna 
Así, dado que no se advierte ninguna norma que establezca alguna sanción para quienes no apliquen la jurisprudencia obligatoria, entonces podría decirse que, en principio, una eventual inaplicación no podría considerarse como ilícita. Sin embargo, en caso de que el Consejo de la Judicatura Federal llegara a determinar lo contrario, sería pertinente tomar en cuenta lo siguiente: La tesis positiva que se ha venido desarrollando en este análisis supone un cambio en el entendimiento que hasta ahora se ha tenido con respecto a la obligatoriedad de la jurisprudencia. De acuerdo con este cambio, tendría que considerarse que la inaplicación de la jurisprudencia podría haberse llevado a cabo a partir de una correcta observancia de la facultad de inaplicación, o bien de manera incorrecta. La corrección o incorrección podría ser determinada por el órgano revisor. De este modo, por ejemplo, podría considerarse que la inaplicación es incorrecta cuando el operador no ofrece razones para justificar su decisión, o si se advierte que las razones que aduce son claramente inaceptables o irrazonables.

Por otro lado, no se desconoce la figura de la delegación de asuntos de competencia originaria del pleno de la Corte a las Salas y a los tribunales colegiados cuando sobre tales asuntos exista jurisprudencia al respecto, de acuerdo con la fracción III del punto segundo del Acuerdo General 5/2013, emitido por el pleno de la Suprema Corte de Justicia de la Nación el 13 de mayo de 2013. Podría argumentarse que si se admitiera la posibilidad de inaplicar la jurisprudencia, entonces la delegación a que se refiere el Acuer-

persona, del mismo u otro poder./ II. Inmiscuirse indebidamente en cuestiones del orden jurisdiccional que competan a otros órganos del Poder Judicial de la Federación./ III. Tener una notoria ineptitud o descuido en el desempeño de las funciones o labores que deban realizar./ IV. Impedir en los procedimientos judiciales que las partes ejerzan los derechos que legalmente les correspondan en los procedimientos./ V. Conocer de algún asunto o participar en algún acto para el cual se encuentren impedidos./ VI. Realizar nombramientos, promociones o ratificaciones infringiendo las disposiciones generales correspondientes./ VII. No poner en conocimiento del Consejo de la Judicatura Federal cualquier acto tendiente a vulnerar la independencia de la función judicial./ VIII. No preservar la dignidad, imparcialidad y profesionalismo propios de la función judicial en el desempeño de sus labores./ IX. Emitir opinión pública que implique prejuzgar sobre un asunto de su conocimiento./ X. Abandonar la residencia del tribunal de circuito o juzgado de distrito al que esté adscrito, o dejar de desempeñar las funciones o las labores que tenga a su cargo./ XI. Las previstas en el artículo 8 de la Ley Federal de Responsabilidades Administrativas de los Servidores Públicos, siempre que no fueren contrarias a la naturaleza de la función jurisdiccional./ XII. Incumplir las disposiciones constitucionales y legales en materia de propaganda y de informes de labores o de gestión, y/ XIII. Las demás que determine la ley. 
do General 5/2013 quedaría prácticamente anulada, pues la razón de esa figura está fundada en la certeza que da el sistema de obligatoriedad de la jurisprudencia, en el sentido de que los tribunales colegiados resolverán los casos concretos observando irrestrictamente la jurisprudencia. No obstante, la inaplicación, lejos de anular el espíritu del acuerdo referido, podría racionalizarlo, pues en este nuevo modelo la Corte ejercerá aquella facultad conociendo de antemano que la autoridad de su jurisprudencia depende de las razones expresadas en ella y no sólo de la autoridad jerárquica que ostenta. Habrá muchos casos en los cuales los tribunales colegiados encontrarán buenas razones para seguir la jurisprudencia, pero habrá otros casos, seguramente minoritarios, en los que algún criterio jurisprudencial no sea convincente, y el tribunal colegiado considere que resulta inconvencional o inconstitucional.

Tampoco se desconoce que mediante la solicitud de ejercicio de la facultad de atracción — contenida en el artículo 107, fracción V, último párrafo, y VIII, inciso b), segundo párrafo, de la Constitución federal— sería posible que la Suprema Corte conociera de la posible inconstitucionalidad o inconvencionalidad de la jurisprudencia, por lo cual sería innecesaria la inaplicación. Al respecto, podría decirse que la solicitud del ejercicio de la facultad de atracción no es un deber irrestricto de los tribunales colegiados, pues la propia Constitución establece que se trata de una posibilidad a consideración del solicitante (establece "que podrá", no que "deberá"). Por lo tanto, no hay incompatibilidad alguna entre ese mecanismo y la facultad de inaplicación de la jurisprudencia. Lo que sí se genera, a partir de este nuevo modelo es, desde luego, que los tribunales colegiados podrían no sentirse obligados a seguir, sin cuestionamientos, los criterios jurisprudenciales que les resulten obligatorios, sino que ahora han de considerarse lo suficientemente capaces para criticarlos y, eventualmente, inaplicarlos si tienen buenas razones - suficientes para derrotar las razones del criterio jurisprudencial - para considerar que tales criterios son violatorios de algún derecho humano de fuente constitucional y/o convencional.

Antes de concluir, es importante aclarar que el alcance de nuestra tesis está dirigida a justificar la facultad de los tribunales colegiados para inaplicar la jurisprudencia cuando ejerzan su atribución de control concentrado, dado que en la contradicción de tesis 299/2013, de la que surge esta reflexión, tuvo como punto de partida dos casos resueltos mediante, precisamente, el control concentrado. Sin embargo, si se toma en cuenta que uno de los 
tribunales contendientes se pronunció sobre la posibilidad de que cualquier autoridad facultada para ejercer control difuso de convencionalidad o constitucionalidad de normas también podría hacerlo con respecto a la jurisprudencia, entonces la reflexión sobre el alcance debería extenderse. En este sentido, el alcance impactaría en toda la concepción del control difuso de constitucionalidad y convencionalidad que es posible hacer sobre normas de fuente legislativa y jurisprudencial.

En resumidas cuentas, la jurisprudencia, sin perder su carácter de obligatoria, puede ser inaplicada cuando, mediante una adecuada motivación, el órgano jurisdiccional determine que es contraria a una norma de derechos humanos de fuente constitucional o pactada internacionalmente; con la reserva, desde luego, de que, de acuerdo con el sistema de revisión existente, esta decisión de inaplicación pueda ser rechazada o confirmada posteriormente.

Lo anterior no significa que debamos admitir que el orden jurídico vaya a quedar subvertido, ya que cualquier ejercicio de inaplicación está necesariamente sujeto a una justificación racional y razonable, en la que la carga argumentativa aumenta significativamente para quien decida dar un paso como ese. A final de cuentas, el control difuso no es otra cosa que un concierto discursivo racional en el que se considera a los jueces ordinarios como capaces y dignos de justificar una decisión de esta magnitud.

Por lo demás, el sistema y las instituciones mantienen su sentido orgánico, ya que contamos con un sistema de revisiones e instancias que permiten evaluar las eventuales inaplicaciones de jurisprudencia a cargo de los jueces y tribunales ordinarios y federales. Así, no podemos suponer que se nos vendrá encima el caos y la anarquía en los criterios, puesto que, a final de cuentas, desde el punto de vista orgánico, nuestro Poder Judicial tiene la capacidad de autorregularse y restringirse.

A partir de todo lo anteriormente señalado, concluimos que la jurisprudencia, como norma jurídica que interpreta de manera directa los derechos humanos contenidos en la Constitución y los tratados, puede ser inaplicada por los tribunales colegiados de circuito siempre que los mismos lo hagan siguiendo los pasos establecidos para ello, razonando de manera puntual la justificación y el fundamento para esta inaplicación, y que resulta ya inaceptable la concepción de la jurisprudencia emitida por la Suprema Corte de Justicia como una norma intangible, infalible y que indefectiblemente contiene la interpretación final de un derecho humano, ya que es una con- 
cepción frontalmente contraria a la reforma constitucional al artículo 10 . de la Constitución y a la concepción de los derechos que resultan de ella.

\section{BIBLIOGRAFÍA}

Alchourrón, Carlos E. y Bulygin, Eugenio, "Norma jurídica", Enciclopedia iberoamericana de filosofía, vol. 11: El derecho y la justicia, Madrid, Trotta, 1996.

AtIEnZA, Manuel, "Algunas tesis sobre la analogía en el derecho", Doxa. Cuadernos de Filosofía del Derecho, Alicante, núm. 2, 1985. -, "Constitución y argumentación", Anuario de Filosofía del Derecho, núm. 24, 2007.

_, El derecho como argumentación, Barcelona, Ariel, 2006.

Cossío Díaz, José Ramón, "Las trampas del consenso", Nexos, 1o. de octubre de 2013.

, "Liberalismo, Constitución y constitucionalismo. Los extremos de una compleja relación", en AGUILAR RIVERA, José Antonio (coord.), La fronda liberal. La reinvención del liberalismo en México (19902014), México, Taurus, 2014.

, "Primeras implicaciones del caso Radilla", Cuestiones Constitucionales. Revista Mexicana de Derecho Constitucional, núm. 26, juniodiciembre de 2012.

—, La controversia constitucional, México, Porrúa, 2008.

— et al., El caso Radilla. Estudio y documentos, México, Porrúa, 2013.

DwORKIN, Ronald, El imperio de la justicia, trad. de Claudia Ferrari, Barcelona, Gedisa, 1997.

EzQuiagA, Francisco Javier, "Argumentos interpretativos y postulado del legislador racional”, Isonomía, México, núm. 1, octubre de 1994.

GUASTINI, Riccardo, “La 'constitucionalización' del ordenamiento jurídico: el caso italiano", Estudios de teoría constitucional, trad. de José María Lujambio, México, Fontamara, 2001. 
, Estudios sobre la interpretación jurídica, trad. de Marina Gascón y Miguel Carbonell, México, UNAM, Instituto de Investigaciones Jurídicas, 1999.

LIFANTE, Isabel, La interpretación jurídica en la teoría contemporánea del derecho, Madrid, Centro de Estudios Políticos y Constitucionales, 1999.

Fecha de recepción: 24 de octubre de 2014.

Fecha de dictamen: 26 de noviembre de 2014. 